\title{
The selection of indicators and criteria for the intellectual level of the Electronic logistics-information systems
}

\author{
Siyka Demirova ${ }^{1}$ and Emil Entchev ${ }^{2}$ \\ ${ }^{1}$ Department of Industrial Management, Technical University of Varna, Bulgaria \\ ${ }^{2}$ Department of Automation of Discrete Production \\ Technical University of Sofia \\ Bulgaria
}

\begin{abstract}
The methodology of digital intelligence sets out a number of requirements or conditions easily conducive to the normal functioning of the logistics information system. More precisely, they refer to a set of indicators that meet the required intellectual level of the logistics system (artificial intelligence). Stated otherwise, the selected indicators should encourage the adoption of a more universal approach when selecting and systematizing intellectual objects according to their significance. This, in turn, creates the necessary prerequisites for the widespread use of mathematical methods and electronic means to prompt the processing of maximum possible volume of information. On that account, the purpose of the present paper is to advance a different approach to the selection of indicators and criteria so that they would be consistent with the intellectual level of the electronic logistics-information systems (E-LIS) in their evaluation and classification of the logistics objects according to their significance.
\end{abstract}

Key Words: Electronic logistics-information systems, Digitilisation of E-LIS, Indicators, Criteria for E-LIS.

\section{INTRODUCTION}

\subsection{Selection of Indicators}

What necessitates such a requirement is the preliminary structuring of the technical levels of the system. This aspect of analytical consideration indicates that the logistics-information system strives to modify the following levels: Technical level of the system (ELIS); Technical level of the object (virtual or real logistics information object); Artificial intelligence (managing intelligence) that comprises:

-Range of functions artificial intelligence can perform (1 ...n).

- Functions, where human activities are fully displaced ( $\mathrm{F}$ of the total number of $n$-functions).

- Functions, where human activities are partially displaced ( $\mathrm{G}$ of the total number of $n$-functions).

\section{CRITERIA THAT HELP DETERMINE THE OBJECTS FOR INTRODUCTION OF DIGITAL INTELLIGENCE}

The selection of the objects starts with careful examination and analysis of their current state. The primary objective of the research is to specify the information and technical parameters of the objects under study according to requirements for their future development. To that effect, their technical level ought to be determined not only at a given point of time, but also in the dynamics over the years to come. Finally, and just as importantly, provisions should also be made for the normative reference base, applied for the establishment and selection of these indicators, to be integrated into the set of studies described so far.

\subsection{Determining the Number of Criteria}

For the criteria to be a satisfactory representation of the state of the surveyed object, their number and the specific context framework should be pursuant to the system requirements. Appreciating the significance of the separate criteria, laying down the necessary condition for further justification of the preference for one choice over another, is sustained by the goal preset in advance and towards which all their endeavours are directed. 
The type and number of the criteria involved in the selection of E-LIS object is normally specified by the particular methods and principles applied in the evaluation of the technical level of the related logistics system. With respect to the primary selection, the criteria have to fulfill the "necessity" and "acceptability" conditions restricting the selection of objects considered adequate for the introduction of digital intelligence. The set of criteria referring to the "necessity" condition has been set out to comprise:

-the criteria for the level of the system;

-the criteria for the level of digitilisation;

-the criteria for the technical level of the object;

-the criteria for the level of the information potential;

- specific criteria distinctive to certain types of objects.

As for the significance of the criteria that relate to the condition of "acceptability" in the selection of objects, it is determined by the following inequality:

$$
\begin{gathered}
N c e \geq C c e \\
T p \geq N p
\end{gathered}
$$

where:

- calculated coefficient of efficiency;

- normative coefficient of efficiency;

- calculated period of time for return on investment;

- normative period of time for return on investment.

\subsection{Calculation of Criteria}

The calculation of the criteria specific to the selection of the objects is carried out in the following sequence:

- preliminary or approximate calculation of criteria ;

- verification of compliance with the condition of "necessity" for digital intelligence (robot);

- verification of adherence to the condition of "acceptability" assigned to the accomplished selection of every single condition related to "acceptability";

- final evaluation of criteria.

The overall activities associated with the identification and calculation of the criteria for the selection of objects for digital intelligence may be arranged as follows:

Sequence of object selection

The selection of objects is implemented in the following sequence:

- systematic structural research and analysis of the relevant objects;

- preliminary selection of the objects;

- classification of the objects according to their techno-economic/technical and economic significance;

- final selection and ranking of the objects.

Systematic-structural research and analysis

The systematic structural research study and analysis of the appropriate objects has been effectively conducted through the use of the respective methodology for determining the E-level of the system and the relevant methodological guidelines for its successful application. The results have been displayed in a specially designated table:

\begin{tabular}{|c|c|c|c|c|c|c|c|c|c|c|c|c|}
\hline \multirow[t]{3}{*}{$\begin{array}{c}\text { Object } \\
\text { Number }\end{array}$} & \multicolumn{5}{|c|}{$\begin{array}{c}\text { Elements Of The Object } \\
\text { Expressed By Criteria }\end{array}$} & \multicolumn{3}{|c|}{ Structural Labor Intensity } & \multicolumn{2}{|c|}{$\begin{array}{c}\text { Human } \\
\text { Labor } \\
\text { Including } \\
\text { Intellectual }\end{array}$} & \multicolumn{2}{|c|}{$\begin{array}{c}\text { Criterion } \\
\text { Digital } \\
\text { Intelligence }\end{array}$} \\
\hline & \multicolumn{5}{|c|}{$A$} & \multicolumn{3}{|c|}{$B$} & \multicolumn{2}{|c|}{$C$} & \multicolumn{2}{|c|}{$D$} \\
\hline & Ls & $L t$ & Lo & Hpp & $S$ & $\sum T_{i}^{M}$ & $\sum T_{H i}{ }^{M}$ & $\sum T_{H i}^{W}$ & $t_{b}$ & $t_{t}$ & $d_{t}$ & $d_{h}$ \\
\hline & $1 . . n$ & $1 . . k$ & $1 . . i$ & $1 . j$ & $1 . . q$ & & & & & & & \\
\hline
\end{tabular}

Table 1.1: Systematic structural research and analysis of objects

where:

A,B,C,D - set of criteria;

Ls - complex criterion for the level of the system;

$\mathrm{Lt}$ - complex criterion for the level of the applied information technology; 
International Journal of Advances in Scientific Research and Engineering (ijasre), Vol 5 (3), March-2019

Lo - complex criterion for the level of the object;

Hpp - complex criterion for the system's potential;

$\mathrm{S}$ - specific indicator (used in the methodology for determining the E-level of the given object);

$\sum T_{i}^{M}$ - cumulative time of the $\mathrm{i}^{\text {-th }}$ object;

$\sum T_{H i}{ }^{M}$ - cumulative time of the $\mathrm{i}^{\text {-th }}$ object, whose activities do not non-overlap with those performed by men (intellectual capabilities);

$\sum T_{H i}{ }^{W}$ - aggregate labour-intensity of the object;

$t_{b}$ - cumulative time of the human labour (incl. the intellectual) within the object;

$t_{t}$ - cumulative time of the intellectual labour within the object;

$d_{t}-$ criterion for the state of labour determined by the formula:

$$
d_{t}=\frac{\sum T_{H}{ }^{M}}{\sum T^{W}}
$$

$d_{h}-$ criterion for the state of the process, that may be determined by the formula:

$$
d_{h}=\frac{\sum T^{M}}{\sum T^{W}}
$$

Introduced upon the secondary selection of a digital object are two further (supplementary) criteria. "Usability" and "Efficiency" are generally recognized as the most appropriate/relevant criteria. All in all, the criteria applied in the study are as follows:

1.Usability

2.Necessity

3.Acceptability

4.Efficiency

The above criteria are dependent upon the requirements and conditions that are necessary to overcome the barriers related to the formation, implementation and usage of technical solutions (artificial intelligence) in practice. The criteria described above are with a more general character, covering a wide range of concepts and encompassing the greatest number of effects. These are precisely the effects that are constantly evolving and ever-changing in one direction or another, but, on the whole, we can safely assume that they predominantly indicate an upward development and infer, accordingly, that they provide a brand new innovative (technical) solution that when adopted in practice will yield the desired effect. Figure 2.1 outlines the criteria and indicators for the selection of objects to be applied in E-LIS.

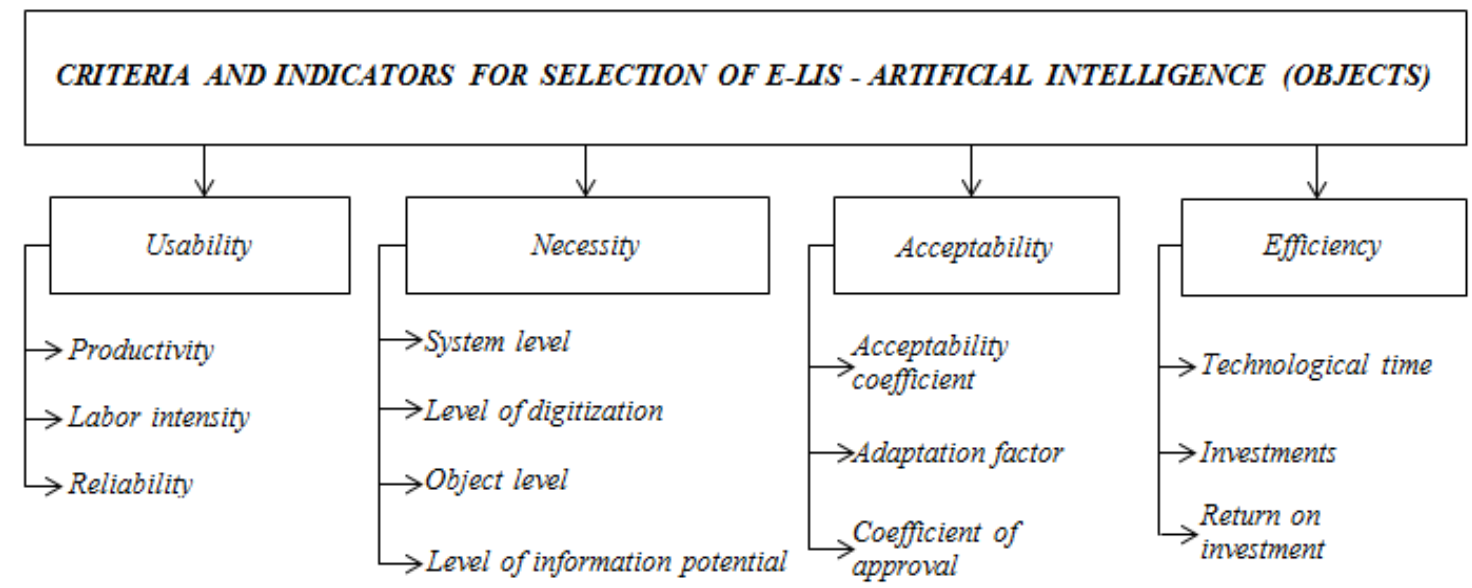

Figure 2.1: Criteria and indicators for the selection of E-LIS- artificial intelligence

The successive order of the process of selection is as follows:

- verification of the "usability" as an essential precondition

The indicators the criterion comprises are: 
International Journal of Advances in Scientific Research and Engineering (ijasre), Vol 5 (3), March-2019

1.Productivity

2.Labour intensity

3. Reliability

4.Other

They are calculated by the relations given below: -productivity:

$$
Q=\frac{Q_{N}}{Q_{O}}
$$

$$
Q=\text { units / hour }
$$

where:

$Q_{N}$ - productivity in the new situation;

$Q_{O}$ - productivity in the old situation.

-labour intensity:

$$
\left.T=\frac{T_{N}}{T_{O}} \quad \text { (from } 0,1 \text { to } 1,0\right)
$$

where:

$T_{N}$ - labour intensity in the new situation;

$T_{O}$ - labour intensity in the old situation.

-reliability:

$$
R \varphi=\frac{R \varphi_{N}}{R \varphi_{O}}(\text { from } 1 \text { upwards })
$$

where:

$R \varphi_{N}$ - reliability in the new situation;

$R \varphi_{O}$ - reliability in the old situation.

- "necessity" criterion extending over the:

1.Level of the system

2. Level of digitilisation

3. Level of the object

4. Level of the information potential

5.Specific indicator

-level of the system:

$$
\left.S=\frac{S_{O}}{S_{N}} \quad \text { (from } 0,1 \text { to } 1,0\right)
$$

where:

$S_{O}$ - level of the system in the old situation;

$S_{N}$ - level of the system in the new situation.

- level of digitilisation:

$$
D=\frac{D_{O}}{D_{N}}(\text { from } 0,1 \text { to } 1,0)
$$

where: 
$D_{O}$ - level of digitilisation in the old situation;

$D_{N}$ - level of digitilisation in the new situation.

- level of the object:

$$
O=\frac{O_{O}}{O_{N}}(\text { from } 0,1 \text { to } 1,0)
$$

where:

$O_{O}$ - level of the object in the old situation;

$O_{N}$ - level of the object in the new situation.

- level of the information potential:

$$
I p=\frac{I p o}{I p n}(\text { from } 0,1 \text { to } 1,0)
$$

where:

Ipo - level of the information potential in the old situation;

Ipn - level of the information potential in the new situation.

- "acceptability" criterion integrating the following indicators:

1.Coefficient of acceptability.

2.Factor of adaptation.

3.Coefficient of approval.

$$
C a=\frac{C a o}{C a n}^{- \text {coefficient of acceptability: }}
$$

where:

Cao - coefficient of acceptability in the old situation;

Can-coefficient of acceptability in the new situation;

- factor of adaptation:

$$
F a=\frac{F a o}{F a n}
$$

where:

Fao - factor of adaptation in the old situation;

Fan - factor of adaptation in the new situation.

where:

$$
\text { Cap }=\frac{\text { Capo }}{\text { Capn }}
$$

Capo - coefficient of approval in the old situation;

Capn - coefficient of approval in the new situation.

- "Efficiency" criterion that refers to the:

1.Technological time

2.Investments

3.Return on investment

- technological time: 
International Journal of Advances in Scientific Research and Engineering (ijasre), Vol 5 (3), March-2019

- investments:

$$
\mathrm{N}=1,2,3 \ldots \ldots \ldots . \mathrm{n} \text { months }
$$

$$
\mathrm{P}=1,2,3 \ldots \ldots \ldots . \mathrm{n} \text { leva }
$$

- return on investment:

$$
R=\frac{Q}{n} ; Q=A . n
$$

where:

$Q$ - the amount invested;

$A$ - deductions (depreciation expenses);

$n$ - years.

\subsection{Artificial Intelligence Functionality}

Artificial intelligence is highly effective in logistics information system for the provision of efficient customer service [1,2,3]. From that perspective, the components of the logistics information service initiated through the Internet, tend to be identified and classified as: Service - Time; Service - Logistics price; Service - transport and processing; Service - Storage; Service Expenditure on shortage and delay; Service - Total costs of the logistics system including other components of the information service of the supply chain - accuracy, flexibility, reliability and others $[4,5,6]$.

\section{CONCLUSIONS}

Ultimately, it all points to the conclusion that all information activities related to E-LIS are particularly important to the customer and can therefore be integrated into the provision of enhanced logistics customer service facilitated by the optimum use of artificial intelligence. As specified by the preliminary research studies, the indicators and criteria that come into a sharper focus in the present paper have been reported to have the highest relative percentage of all the factors that affect human performance in the workplace (artificial intelligence). In view of this, selecting the right indicators and criteria that are concurrent with the relevant logistics information system is, therefore, of utmost importance for the use of artificial intelligence not only for the provision of service to customers but also for improving the service quality itself.

\section{REFERENCES}

[1]. D. Damyanov, Trends in Industrial Development and Automation of Discrete Production Processes, Collection of Scientific Papers from Conferences ADP, Sozopol, ISSN 1310 - 3946, 2011, pp. 16-23

[2]. D. Damianov, Chukalov K., Structural reorganization in the informational-technical system of a production machine (hibrid) for operating in the Industry 4.0, International Scientific Conference "INDUSTRY 4.0", Proceeding XXIV, Volume 27/213 ISSN 1310-3946, pp.42-463.

[3]. D. Damianov, Demirova S., Principles of designing automated logistics systems - hybrid component of cyber-physical systems, International Conference on High Technology for Sustainable Development, HiTech 2018, /SCOPUS/IEEE, DOI:10.1109/HiTech.2018.8566533, ISBN 978-153867039-2

[4]. P.R. Murphy \& Daley, J.M. (2001) "Profiling international freight forwarders: an update", International Journal of Physical Distribution and Logistics Management, Vol. 31, No. 3, pp. 152-168

[5]. S.A. Mattsson, (2004). Logistikens termer och begrepp Stockholm: PLAN Föreningen för Produktionslogistik

[6]. C. Bienstock, Royne M., Sherrell D., Stafford T., An expanded model of logistics service quality: Incorporating logistics information technology, International Journal of Production Economics, Volume 113, Issue 1, 2008, Pages 205-222

[7]. A.M. Karminsky., Information systems in economics, 2006

[8]. M. Maslarich, Svetlana Nikolichic and Dejan Mirchetic, Logistics Response to the Industry 4.0: the Physical Internet, Open Eng. 2016; 6:511-517

[9]. R. Moreno-Vozmediano, Montero R.S., Llorente I.M., Key challenges in cloud computing: Enabling the future internet of services, IEEE Internet Comput, 17 (4) (2013), pp. 18-25 